Academic Platform Journal of Engineering and Science

\title{
Membran Kapasitif Deiyonizasyon Prosesi ile Sertlik Giderimi
}

\author{
*1Halil İbrahim Uzun, ${ }^{2}$ Eyüp Debik \\ ${ }^{1}$ Muş Alparslan Üniversitesi, Mühendislik Mimarlık Fakültesi, Çevre Mühendisliği Bölümü, ha.uzun@ alparslan.edu.tr (iD \\ ${ }^{2}$ Yıldız Teknik Üniversitesi, İnşaat Fakültesi, Çevre Mühendisliği Bölümü, debik@yildiz.edu.tr (D)
}

Araştırma Makalesi

Geliş Tarihi: 03.12.2018

Kabul Tarihi: 23.052019

\section{$\ddot{O} z$}

Kalsiyum ve Magnezyum elementlerinin (+2) değerlikli iyon halleri sularda sertlik oluşturmaktadır. İnsan sağlığı açısından ciddi riskler oluşturmasa da sert sular sanayide üretim kalitesinin düşmesi, boruların ömrünün azalması, sıcak su üreten ya da tüketen cihazların ömrünün azalması gibi olumsuzluklara sebep olur. Sular $\mathrm{CaCO}_{3}$ eşdeğeri olarak $(0-75 \mathrm{mg} / \mathrm{L})$ yumuşak, $(75$ - $150 \mathrm{mg} / \mathrm{L})$ orta sert, $(150-300 \mathrm{mg} / \mathrm{L})$ sert, $(>300 \mathrm{mg} / \mathrm{L})$ çok sert su şeklinde sınıflandırılmaktadır. Membran Kapasitif deiyonizasyon (MCDI), sertlik türlerinin giderilmesinde etkili bir prosestir. Bu çalışmada sertlik gideriminde arıtılmış suyun kullanım alanı da göz önünde bulundurularak çok sert su sınıfına giren farklı oranlarda $\mathrm{Ca}^{2+} \mathrm{ve}^{\mathrm{Mg}^{2+}}$ içeren sular MCDI ile arıtılarak proses suyu ve içme suyu elde edilmeye çalışılmıştır. Çalışmalar neticesinde $300 \mathrm{mg} \mathrm{CaCO} / \mathrm{L}$ sertlik içeren sular proses suyu üretiminde $\% 90$ - \%97 aralığında; içme suyu eldesinde ise $\% 71$ - \%82 oranlarında arıtılmıştır. Enerji için Maliyet analizi yapıldığında proses suyu için maliyetler $0,01-0,02 \$ / \mathrm{m}^{3}$ aralığında değişirken içme suyu eldesi için bu maliyet 0,009 $0,016 \$ / \mathrm{m}^{3}$ aralığında değişmektedir.

Anahtar kelimeler: Sertlik, Membran Kapasitif Deiyonizasyon, Tuzsuzlaştırma

\section{Hardness Removal by Membrane Capacitive Deionization Process}

\author{
${ }^{* 1}$ Halil Ibrahim Uzun, ${ }^{2}$ Eyup Debik \\ ${ }^{1}$ Muş Alparslan University, Faculty of Engineering and Architecture, Environmental Engineering Department, \\ ha.uzun@alparslan.edu.tr ii \\ ${ }^{2}$ Ylldız Technical University, Civil Engineering Faculty, Environmental Engineering Department, debik@yildiz.edu.tr
}

\begin{abstract}
Calcium and Magnesium elements (+2) valued ion states form hardness in waters. Although it does not pose serious risks for human health, hard water causes negative effects such as decreasing production quality in the industry, shorten the life of the pipes and the life of the devices that produce or consume hot water. Water is classified as $\mathrm{CaCO} 3$ equivalent $(0-75 \mathrm{mg} / \mathrm{L})$ soft, $(75-150 \mathrm{mg} / \mathrm{L}$ ) medium hard, (150 - $300 \mathrm{mg} / \mathrm{L})$ hard, ( >300 mg / L) as hard water. Membrane Capacitive deionization (MCDI) is an effective process for removing hardness types. In this study, taking the usage area of treated water in hardness removal, into account, water with different proportions of $\mathrm{Ca}^{2+}$ and $\mathrm{Mg}^{2+}$, which are classified as hard water, have been treated with MCDI to produce process water and drinking water. As a result of the studies, water containing $300 \mathrm{mg} \mathrm{CaCO}_{3} / \mathrm{L}$ hardness in the process water production in the range of 90\% - 97\%; in drinking water treatment, it was treated with\% $71-\%$ 82. When cost analysis is performed, costs for process water vary between $0.01-0.02 \$ / \mathrm{m}^{3}$, while this cost for drinking water varies between $0.009-0.016 \$ / \mathrm{m}^{3}$.
\end{abstract}

Keywords: Hardness, Membrane Capasitive Deionization, Desalination

\section{GİRIŞ}

Suların sertliği, muhtevasında bulunan iki değerlikli metal katyonlarının sebep olduğu, suyun temas ettiği yüzeylerde tahribata yol açan, suyun tadını bozan ve su kalitesini belirleyen bir parametredir [1]. Sertlik su içinde çözünen $\mathrm{Ca}^{2+}, \mathrm{Mg}^{2+}, \mathrm{Sr}^{2+}, \mathrm{Fe}^{2+}, \mathrm{Mn}^{2+}$ gibi iki değerlikli iyonların konsantrasyonlarına bağlıdır. Söz konusu bu iyonların $\mathrm{HCO}_{3}^{-}, \quad \mathrm{SO}_{4}^{2-}, \mathrm{Cl}^{-}, \quad \mathrm{NO}_{3}^{-}, \mathrm{SiO}_{3}^{-}$gibi anyonlar ile oluşturdukları tuzlar sertliği meydana getirir. Sulardaki

\footnotetext{
*11Muş Alparslan Üniversitesi, Mühendislik Mimarlık Fakültesi, Çevre Mühendisliği Bölümü, ha.uzun@ alparslan.edu.tr,

Bu çalışma ISEM2018 sempozyumunda " Membran Kapasitif Deiyonizasyon Prosesi ile Sertlik Giderimi " başlıklı bildiri olarak sunulan çalışmadan geliştirilmiştir.
} 
sertlik, suların temas halinde bulunduğu kayaç veya toprak dolayısı ile oluşur. Sular temas ettikleri sertlik kaynağı olan maddeleri çözerek bünyesine alır. Böylelikle sertlik oluşur. Özellikle yağışlar sırasında yağmur suları atmosfer gazları ile birleşerek asidik karaktere sahip olmaktadır. Bunun yanında toprakta meydana gelen biyolojik faaliyetler sonucunda açığa çıkan $\mathrm{CO}_{2}$ suda çözünerek ona asidik bir karakter kazandırabilir [2].

Endüstriyel ve içme ihtiyacına yönelik kullanılacak olan sert suların arıtılması hem suların kullanım amaçları yönünden hem de suların nefaseti dolayısı ile önemlidir. Özellikle sertlik oluşturan kalsiyum ve magnezyum gibi +2 değerlikli iyonlar sıcak su kullanan veya üreten teknolojik ekipmanların borulama sistemlerinde ciddi tıkanmalara sebep olmaktadır [3]. Ayrıca arıtma sistemlerinde membranların kirlenerek ve tıkanarak işlevlerini kaybetmesi, kazan taşı oluşumu, temizlik verimliliğinde azalma, temizlik kimyasallarının sarfiyatında artış gibi problemlerin azaltılması ve giderilmesinde sertlik giderimi oldukça önemlidir [4]. Ancak suların arıtılmasında ve özellikle sertlik gideriminde suyun kullanım alanı oldukça önemlidir.

Endüstiyel ihtiyaca yönelik kullanılacak sulardan tüm iyonların giderilmesi istenebilir. Ancak içme sularında kalsiyumun ve magnezyumun sağlık açısından bilinen olumsuz bir etkisi bulunmamaktadır. Diğer taraftan kalsiyum insan vücudu için gerekli minerallerden biridir. Kemik yapısına katılmakla birlikte periferik sinirlerde ve kaslarda işlevin normal devamı için rol oynar. Magnezyum ise vücutta fosfat transferinde önemli rol oynayan elementlerden biridir. Ayrıca nükleik asitlerin yapısal düzenlerinin korunmasında önemli bir element olduğu kabul edilmektedir [5].

Sulardan sertlik gideriminde kimyasal çöktürme, iyon değiştirme, nanofiltrasyon ve ters ozmoz gibi memran prosesleri ile elektrodiyaliz yaygın olarak kullanılan ve artık geleneksel arıtma sistemleri olarak ifade edilen proseslerdir [6]-[12].

Ancak kimyasal çöktürme işleminde kullanılan ilave kimyasallar içme sularında kısıtlanan maddelerdir. İyon değişimi ve membran işlemlerinin rejenerasyonunda açığa çıkan tek değerlikli iyonlar ve asitler, çevreye zararlı etkilere neden olmaktadır [4], [10], [13]. Bu arıtma yöntemleri arıtma yönteminin doğrudan kimyasal bir işleme dayanması, membranları meydana gelecek tıkanmaların azaltılmasinda ve giderilmesinde kullanılan kimyasallar gibi ekstra kimyasal kullanımını gerektirmesi, enerji maliyetlerinin yüksek olması gibi dezavantajlar dolayısı ile ekonomik gözükmemektedir [12]. Bu sebeple sert suların arıtılmasında çevre dostu, esnek kullanıma sahip, düşük enerji maliyetleri olan arıtma yöntemlerine ihtiyaç duyulmaktadir.

Son yıllarda sert suların kontrolünde etkili bir alternatif olarak gösterilen kapasitif deiyonizasyon (CDI) elektrotlar üzerinde elektrokimyasal adsorpsiyon / desorpsiyon yoluyla iyonların bertaraf edildiği bir teknolojidir [14]-[16]. CDI prosesinde uygulanan potansiyeller ile anot ve katot olarak ayrılan elektrotların yüzeyleri üzerinde zıt yüklü iyonları tutmak için elektriksel çift tabaka oluşturulur. Böylelikle zit yüklü iyonlar karşıt elektrotlarda etkili bir biçimde tutulurlar. Kapasitif deiyonizasyon (CDI) nispeten düşük enerji tüketen, sertlik iyonlarının uzaklaştırılması için oldukça cazip, çevre dostu bir teknolojidir ve ikincil rejenerasyon atıkları oluşturmaz, pahalı membranlar ve yüksek basınç pompaları gerektirmez [17], [18].

Membran kapasitif deiyonizasyon (MCDI) ise CDI sisteminde elektrot yüzeylerine iyon seçici membran eklenmesi ile oluşturulan ve CDI teknolojisinin performansinı arttırmada etkili olan bir prosestir [19]. İyon seçici membranlar karşıt elektrotlarda zıt yüklü iyonların etkili tutulmasını sağlarken aynı zamanda desorpsiyon sürecinde zit iyonların karşı elektrotlara geçişlerini engellemektedir.

CDI prosesi ile tek değerli iyonların sudan bertarafina yönelik bir çok çalışma yapılmıştır ancak CDI kullanılarak sertliğin giderilmesi üzerine yapılan çalışmalar kısıtlıdır [14], [20], [21].

$\mathrm{Bu}$ çalışmada sertlik oluşturan kalsiyum ve magnezyum iyonları MCDI prosesi ile ekonomik olarak arıtılarak hem proses suyu kalitesine (\%100'e yakın sertlik giderimi) hem de içme suyu kalitesine getirilmeye (\%50 - \%70) çalışılmıştır. MCDI prosesinde iyonların tercihli olarak giderildiği bilinmekte olduğundan kalsiyum ve magnezyum giderim verimleri ayrı ayrı tespit edilmeye çalışılmıştır. Son olarak MCDI ile sertlik gideriminde enerji sarfiyatları ve maliyetler ortaya konmuştur.

\section{MALZEME VE YÖNTEM}

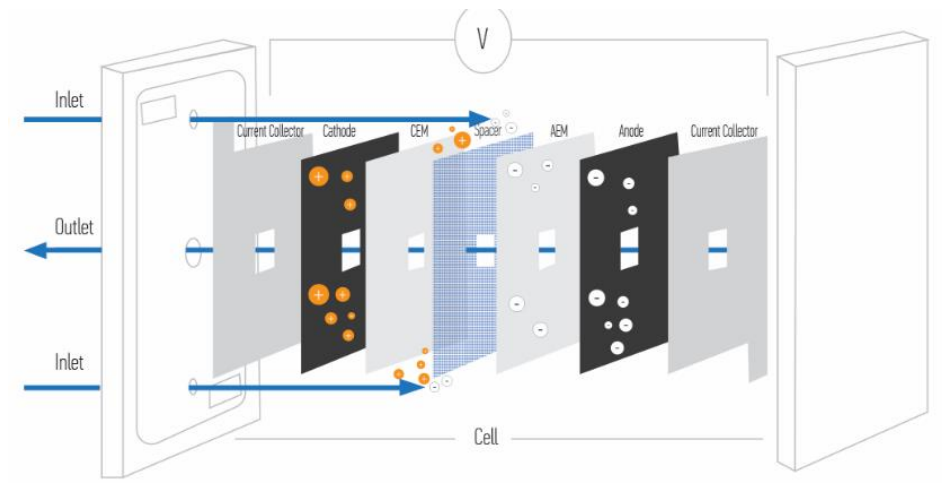

Şekil 1. MCDI şematik gösterimi [22].

MCDI çalışmaları Şekil 1'de şematik olarak gösterilen Voltea marka MCDI sistemi ile yürütülmüştür. MCDI sistemi birbirini takip eden 24 adet hücreden oluşmakta, her bir hücre grafit akım dağıtıcı (kalınlık $\delta=250 \mu \mathrm{m}$ ), kimyasal olarak aynı katot ve anot görevi görmek üzere gözenekli karbon elektrotlar (PACMM 203, Irvine, CA, 
USA, $\delta \mathrm{e}=362 \mu \mathrm{m}$ ), iyon geçişi kontrolünü sağlamak üzere anyon ve katyon seçici membranlar (Neosepta AM-1 and Neosepta CM-1, Tokuyama Co., Japan, $\delta \approx 130 \mu \mathrm{m})$, su akışını sağlaması ve elektrotları birbirinden ayırması için tekstil bir ayırıcı $(\delta=115 \mu \mathrm{m})$ 'dan oluşmaktadır. Toplam elektrot alanı $1,18 \mathrm{~m}^{2}$ ve karbon elektrotların direnci 1 $( \pm 0,2) \Omega \bullet \mathrm{cm}^{2}$ 'dir. Anyon ve katyon seçici membranların dirençleri yaklaşık $2 \Omega \bullet \mathrm{cm}^{2}$ 'dir [23].

MCDI, arıtım (puring), ön hazırlık (prepurifying), desorpsiyon (wasting) şeklinde ifade edilebilecek üç aşamada otomatik ve manuel olarak çalıştırılmaktadır. Aşamaların tamamı aynı reaktörde gerçekleşmek olup fakat bu üç aşamada da arıtılmış su ile konsantre akım farklı kanallardan otomatik olarak yönlendirilebilmektedir.

Ayrıca MCDI cihazında partikül maddelerin reaktör içine girmesini önlemek amaciyla 1L hacme sahip $0,1 \mu \mathrm{m}$ por çaplı filtrenin bulunduğu bir ön arıtım hücresi bulunmaktadır. Reaktörün besleme ve arıtılmış suyun çıkış kanallarında iletkenlik propları bulunmaktadır ve iletkenlikler otomatik olarak ölçülerek yazılım aracılığı ile bilgisayara aktarılmaktadır. Elektriksel potansiyel (V), akım (A) ve basınç gibi değerler otomatik olarak ölçülebilmektedir.

MCDI sisteminde elektriksel potansiyel hidroliz şartlarının oluşmaması için maksimum 1,5 V olacak şekilde sabit tutulmuştur. Cihaz reaktörü $0,3 \mathrm{~L}$ hacminde olduğu için, tam karışımlı bir reaktör kabulü ile debi ve $0,3 \mathrm{~L} / \mathrm{dk}$ 'da tutulmuştur. Bu değerin üstündeki debilerde enerji sarfiyatı artmakta, altındaki değerlerde ön hazırlık aşamasında reaktörün tam olarak boşaltılması uzun sürmektedir. Bu bağlı olarak konsantre akım hacmi artmaktadır. MCDI sistemi ile yapılan optimizasyon çalışmalarında işletme sürelerinin adsorpsiyon için 1440 saniye, sistemin hazırlık aşaması (reaktörde bulunan konsantrenin tamamen bertarafi ve elektrotların adsorpsiyon/desorpsiyon için şarj edilmesi) için 60 saniye olarak tespit edilmiştir. Desorpsiyon süresi giriş iletkenliğine bağlı olarak değişmektedir [24].

$\mathrm{Ca}^{2+}, \mathrm{Mg}^{2+}$ ölçümleri için standart metotlar kullanılmıştır [Standart Methods].

MCDI cihazının, farklı içeriklerde çok sert sınıfında kabul edilen (300 $\mathrm{mg} \mathrm{CaCO}_{3} / \mathrm{L}$ sertliğine sahip su numuneleri) suları arıtma performansının ortaya konması için farklı içeriğe sahip numuneler hazırlanmıştır. İçerikte bulunan $\mathrm{Ca}_{2+}$ ve $\mathrm{Mg}_{2+}$ iyonları $\mathrm{mg} \mathrm{CaCO}_{3} / \mathrm{L}$ eşdeğeri olarak hazırlanmış ve giderim verimleri de bu eşdeğerler üzerinden hesaplanmıştır.

\section{BULGULAR}

\subsection{Farklı Konsantrasyonlarda $\mathrm{Ca}^{2+}$ ve $\mathrm{Mg}^{2+}$ Sertliği Olan Sulardan MCDI ile Proses Suyu Üretimi}

Sular sertlik derecelerine göre sinıflandırılmaktadır. Tablo
1 'de bu sınıflandırma ve konsantrasyonları verilmiştir.

Tablo 1. Suların mg $\mathrm{CaCO}_{3} / \mathrm{L}$ sertlik derecesi siniflandirmasi

\begin{tabular}{|c|c|}
\hline $\mathrm{mg} \mathrm{CaCO}_{3} / \mathrm{L}$ & Sertlik Derecesi \\
\hline $0-75$ & Yumuşak \\
\hline $75-150$ & Orta Sert \\
\hline $150-300$ & Sert \\
\hline 300 ve üzeri & Çok Sert \\
\hline
\end{tabular}

Yaklaşık (1:1), (1:2) ve $(2: 1)$ ve toplam sertliği yaklaşık $300 \mathrm{mg} \mathrm{CaCO} 3$ / L toplam sertliği olan çok sert sınıfina giren MCDI ile \%100'e yakın giderim verimi ile arıtılarak proses suyu (ultra saf) elde edilmeye çalışılmıştır. Hazırlanan çözeltilerin $\mathrm{Ca}^{2+}$ ve $\mathrm{Mg}^{2+}$ iyonlarından kaynaklanan sertlikleri ile toplam sertlikleri Tablo 2'de verilmiştir.

Tablo 2. Hazırlanan Çözeltilerin $\mathrm{Ca}^{2+}$ ve $\mathrm{Mg}^{2+}$ ile Toplam Sertlik Dereceleri

\begin{tabular}{|c|c|c|c|}
\hline $\begin{array}{c}\mathrm{Ca}^{2+}+\mathrm{Mg}^{+2} \\
\text { Giriş } \\
\text { Oranlar1 }\end{array}$ & $\begin{array}{l}\mathrm{Ca}^{2+} \text { Sertliği } \\
\mathrm{mgCaCO}_{3} / \mathrm{L}\end{array}$ & $\begin{array}{l}\mathrm{Mg}^{2+} \\
\text { Sertliği } \\
\mathrm{mgCaCO}_{3} / \mathrm{L}\end{array}$ & $\begin{array}{l}\text { T.S. } \\
\mathrm{mgCaCO}_{3} / \mathrm{L}\end{array}$ \\
\hline $1: 1$ & 155 & 152 & 307 \\
\hline $2: 1$ & 195 & 110 & 305 \\
\hline $1: 2$ & 110 & 190 & 310 \\
\hline $\mathrm{Ca}^{2+}$ & 305 & - & 305 \\
\hline $\mathrm{Mg}^{2+}$ & - & 300 & 300 \\
\hline
\end{tabular}

Farklı oranlarda hazırlanan çözeltiler MCDI cihazı ile proses suyu elde etmek amaciyla ultra saf su üretilecek düzeyde arıtılmıştır.

Elde edilen veriler Tablo 2'de verilmiştir. İletkenlik üzerinden giderim verimleri $\mathrm{Ca}^{2+}: \mathrm{Mg}^{2+}$ için (1:1), (1:2), (2:1) için surasıyla \%97, \%94 ve \%92'dir. Yalnızca $\mathrm{Ca}^{2+}$ iyonlarından ileri gelen sertlik için iletkenlik giderim verimi \%99 iken, yalnızca $\mathrm{Mg}^{2+}$ iyonlarından ileri gelen sertlik için iletkenlik giderim verimi \%92'dir. İyonların elektrotlara göç ettirilmesinde sulu yarı çapları, elektrotların gözenek boyutları ve bu boyutların dağılımları önemlidir. Mikro ve makro gözenek boyutunun dengeli olarak dağıldığı elektrotlarda sulu yarı çapı yüksek olan iyonların daha etkili giderilebileceği söylenebilir [25].

$\mathrm{Mg}^{2+}(4,28 \AA)$ ve $\mathrm{Ca}^{2+}(4,12 \AA)$ sulu yarı çaplarının birbirine yakın olduğu göz önüne alındığında, $\mathrm{Mg}^{2+}$ ve $\mathrm{Ca}^{2+}$ iyonlarının dengeli olarak arıtılabilir. MCDI ile yapılan çalışmalar sonucunda standart hatalar göz önüne alındığında $\mathrm{Ca}^{2+}$ ve $\mathrm{Mg}^{2+}$ iyonlarının dengeli olarak arıtıldığı görülmektedir. 
Tablo 3. MCDI ile proses suyu eldesinde performans göstergeleri

\begin{tabular}{|c|c|c|c|c|c|}
\hline $\begin{array}{c}\mathrm{Ca}^{2+} \text { ve } \mathrm{Mg}^{2+} \text { Sertliği } \\
\text { Oranlar1 }\end{array}$ & $(1: 1)$ & $(2: 1)$ & $(1: 2)$ & $\mathrm{Ca}^{+2}$ & $\mathrm{Mg}^{2+}$ \\
\hline $\begin{array}{c}\text { İletkenlik Giderimi } \\
(\%)\end{array}$ & 97 & 94 & 92 & 99 & 92 \\
\hline Ortalama Akım (A) & 2,1 & 1,7 & 1,9 & 1,65 & 3,1 \\
\hline $\begin{array}{c}\text { Ortalama Potansiyel } \\
(\mathrm{V})\end{array}$ & 1,41 & 1,21 & 1,14 & 1,17 & 1,25 \\
\hline Su Geri Kazanımı (\%) & 91 & 91 & 91 & 91 & 89 \\
\hline $\begin{array}{c}\text { Giriş İletkenliği } \\
(\mu \mathrm{S} / \mathrm{cm})\end{array}$ & 465 & 367 & 531 & 351 & 677 \\
\hline
\end{tabular}

MCDI ile arıtım sonrası kalan $\mathrm{Ca}^{2+}$ ve $\mathrm{Mg}^{2+}$ sertliklerinin mg $\mathrm{CaCO}_{3} / \mathrm{L}$ cinsinden miktarları Tablo 4'de verilmiştir.

Tablo 4. MCDI ile proses suyu eldesinde arıtım sonrası kalan $\mathrm{Ca}^{2+}$ ve $\mathrm{Mg}^{2+}$ iyonlarından kaynaklanan sertlik miktarları

\begin{tabular}{|c|c|c|c|}
\hline $\begin{array}{c}\mathrm{Ca}^{2+}+ \\
\mathrm{Mg}^{+2} \\
\begin{array}{c}\text { Sertlik } \\
\text { Oranlar1 }\end{array}\end{array}$ & $\begin{array}{c}\mathrm{Ca}^{2+} \text { Sertliği } \\
\mathrm{mgCaCO}_{3} / \mathrm{L}\end{array}$ & $\begin{array}{l}\mathrm{Mg}^{2+} \\
\text { Sertliği } \\
\mathrm{mgCaCO}_{3} / \mathrm{L}\end{array}$ & $\begin{array}{c}\text { T.S. } \\
\text { Giderim } \\
\text { Verimi } \\
\%\end{array}$ \\
\hline $1: 1$ & $<1$ & 10 & 97 \\
\hline $2: 1$ & 15 & 7 & 93 \\
\hline $1: 2$ & 5 & 25 & 90 \\
\hline $\mathrm{Ca}^{2+}$ & 15 & - & 95 \\
\hline $\mathrm{Mg}^{2+}$ & - & 20 & 93 \\
\hline
\end{tabular}

Sonuçlara göre Şekil 2'de gösterildiği gibi yaklaşık (1:1) oranında hazırlanan çözelti için $\mathrm{Ca}^{2+}$ ve $\mathrm{Mg}^{2+}$ sertliklerinin giderim verimleri sırasıyla \%100 ve \%93; (1:2) oranında hazırlanan çözelti için sırasıyla \%92 ve \%94; (2:1) oranı için sırasıyla $\% 95$ ve $\% 87$ şeklindedir. Yalnızca $\mathrm{Ca}^{2+}$ veya $\mathrm{Mg}^{+2}$ sertliği içeren çözeltinin arıtılması ile $\mathrm{Ca}^{2+}$ ve $\mathrm{Mg}^{2+}$ sertliklerinin giderim verimleri sırasıyla $\% 95$ ve $\% 93$ 'tür. MCDI ile arıtımda iletkenlik ilk sürücü kuvvet olarak değerlendirmektedir. (1:1) oranında hazırlanan çözeltide bulunan $\mathrm{Ca}^{2+}$ iyonlarının yalnızca $\mathrm{Ca}^{2+}$ iyonları ile hazırlanan çözeltide bulunan iyonlardan daha etkili giderilmesi iletkenlik farklılıklarından kaynaklanmaktadır.

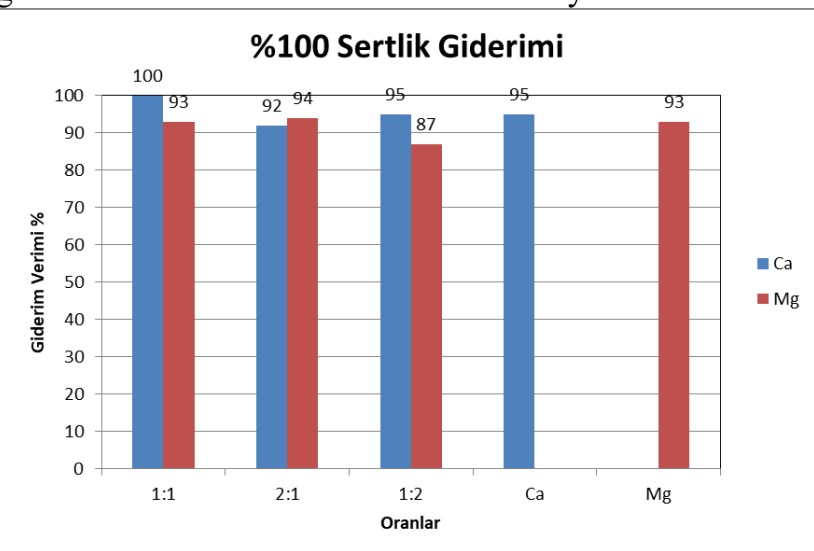

Şekil 2. Proses suyu eldesinde $\mathrm{Ca}^{2+}$ ve $\mathrm{Mg}^{2+}$ giderim verimleri

\subsection{Farklı Konsantrasyonlarda $\mathrm{Ca}^{2+}$ ve $\mathrm{Mg}^{2+}$ Sertliğ Olan Sulardan MCDI ile İçme Suyu Eldesi}

Sertlik giderimi daha önce ifade edildiği gibi suyun kullanım alanına uygun olarak belirlenmelidir. Bu sebeple içme suyu eldesine yönelik çalışmalarda yaklaşık olarak $300 \mathrm{mg} \mathrm{CaCO} / \mathrm{L}$ sertlik içeren suların $75 \mathrm{mg} \mathrm{CaCO}_{3} / \mathrm{L}$ düzeyine indirilerek yumuşatılması hedeflenmiştir.

$(1: 1),(1: 2)$ ve $(2: 1)$ oranında $\mathrm{Ca}^{2+}$ ve $\mathrm{Mg}^{2+}$ iyonları içeren suların MCDI ile arıtılmasinda kullanılan akım ve potansiyel verileri Tablo 5'de gösterilmektedir. Bu veriler ile yapılan arıtım sonrasinda (1:1), (1:2) ve (2:1) oranlarında $\mathrm{Ca}^{2+}$ ve $\mathrm{Mg}^{2+}$ içeren suların arıtılmasında iletkenlik giderim verimleri sirasıla $\% 77, \% 77$ ve $\% 71$ 'dir. Yalnızca $\mathrm{Ca}^{2+}$ iyonu ile hazırlanan çözeltide iletkenlik giderim verimi $\% 78$ ve yalnızca $\mathrm{Mg}^{2+}$ iyonu ile hazırlanan çözeltide iletkenlik giderim verimi \%73'tür.

Tablo 5. MCDI ile içme suyu eldesinde performans göstergeleri

\begin{tabular}{|l|l|l|l|l|l|}
\hline $\mathrm{Ca}^{2+}: \mathrm{Mg}^{2+}$ Oranları & $(1: 1)$ & $(2: 1)$ & $(1: 2)$ & $\mathrm{Ca}^{+2}$ & $\mathrm{Mg}^{2+}$ \\
\hline $\begin{array}{l}\text { İletkenlik Giderimi } \\
(\%)\end{array}$ & 77 & 77 & 71 & 78 & 73 \\
\hline Ortalama Akım (A) & 1,7 & 1,50 & 2,1 & 1,29 & 2,7 \\
\hline $\begin{array}{l}\text { Ortalama Potansiyel } \\
(\mathrm{V})\end{array}$ & 1,2 & 1,1 & 1,3 & 1 & 1,25 \\
\hline Su Geri Kazanımı (\%) & 91 & 91 & 91 & 91 & 86 \\
\hline $\begin{array}{l}\text { Giriş İletkenliği } \\
(\mu \mathrm{S} / \mathrm{cm})\end{array}$ & 465 & 367 & 531 & 351 & 677 \\
\hline
\end{tabular}

Farklı oranlarda kalsiyum ve magnezyum sertliği içeren numunelerin MCDI ile arıtım sonrası kalan $\mathrm{Ca}^{2+}$ ve $\mathrm{Mg}^{2+}$ sertliklerinin $\mathrm{mg} \mathrm{CaCO}_{3}$ / L cinsinden miktarları Tablo 6'da verilmiştir.

Tablo 6. MCDI ile içme suyu eldesinde arıtım sonrası kalan $\mathrm{Ca}^{2+}$ ve $\mathrm{Mg}^{2+}$ iyonlarından kaynaklanan sertlik miktarları

\begin{tabular}{|c|c|c|c|}
\hline $\begin{array}{c}\mathrm{Ca}^{2+}+\mathrm{Mg}^{+2} \\
\text { Giriş } \\
\text { Oranları }\end{array}$ & $\begin{array}{c}\mathrm{Ca}^{2+} \text { Sertliği } \\
\mathrm{mgCaCO}_{3} / \mathrm{L}\end{array}$ & $\begin{array}{l}\mathrm{Mg}^{2+} \text { Sertliği } \\
\mathrm{mgCaCO}_{3} / \mathrm{L}\end{array}$ & $\begin{array}{c}\text { T.S. } \\
\text { Giderim } \\
\text { Verimi } \\
\%\end{array}$ \\
\hline $1: 1$ & 30 & 39 & 77 \\
\hline $2: 1$ & 55 & 25 & 74 \\
\hline $1: 2$ & 24 & 65 & 71 \\
\hline $\mathrm{Ca}^{2+}$ & 54 & - & 82 \\
\hline $\mathrm{Mg}^{2+}$ & - & 82 & 73 \\
\hline
\end{tabular}

(1:1) oranında hazırlanan çözelti için $\mathrm{Ca}^{2+}$ ve $\mathrm{Mg}^{2+}$ sertliği içeren sudaki giderim verimleri sırasıyla $\% 80$ ve $\% 74 ;(1: 2)$ oranında hazırlanan çözelti için sırasıyla \%72 ve \%77; (2:1) oranı için sırasıyla \%78 ve \%66 elde edilmiştir. Sadece $\mathrm{Ca}^{2+}$ ve yalnızca $\mathrm{Mg}^{2+}$ ile hazırlanan numunelerin arıtılması ile $\mathrm{Ca}^{2+}$ ve $\mathrm{Mg}^{2+}$ giderim verimleri sirasiyla \%82 ve 
\%73'tür. Şekil 3'de de gösterildiği gibi sonuçlar ultra saf su eldesinde yapılan çalışmalarla uyumludur.

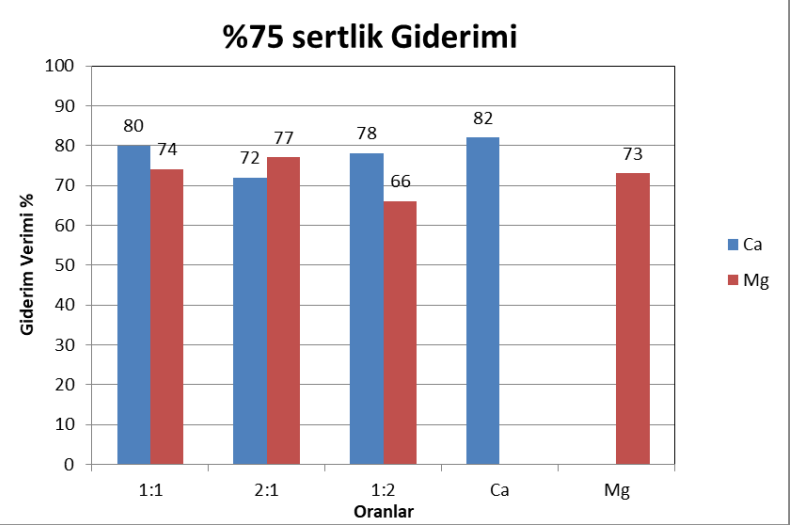

Şekil 3. Proses suyu eldesinde $\mathrm{Ca}^{2+}$ ve $\mathrm{Mg}^{2+}$ sertliklerinin giderim verimleri

\subsection{MCDI ile Sertlik Gideriminde Maliyet}

Daha önce ifade edildiği gibi sulardan sertlik gideriminde, arıtılacak suyun kullanım alanı oldukça önemlidir. Fakat geleneksel sertlik giderim yöntemlerinde sertlik giderim verimi üzerinde esneklik bulunmamaktadır. MCDI prosesiyle yürütülen çalışmalarda da görüldüğü gibi istenen verimde arıtım yapmak mümkündür. $\mathrm{Bu}$ arıtım ekonomisini açısından da oldukça önemlidir. MCDI ile $300 \mathrm{mgCaCO}_{3} / \mathrm{L}$ sertlik içeren suyun $\% 95$ - 100 arasında arıtılarak proses suyu elde edilmesi ile yaklaşık \%75 oranında arıtma veriminde içme suyu özelliğinde su elde edilmesinde toplam enerji sarfiyatı ve toplam maliyet hesaplanarak tabloda verilmiştir.

Tablo 7. MCDI ile sertlik gideriminde enerji sarfiyatları ve maliyetler

\begin{tabular}{|l|c|c|c|c|c|}
\hline & \multicolumn{5}{|c|}{ Proses Suyu Eldesi } \\
\hline $\begin{array}{l}\mathrm{Ca}^{2+}: \mathrm{Mg}^{2+} \\
\text { Oranlar1 }\end{array}$ & $(1: 1)$ & $(2: 1)$ & $(1: 2)$ & $\mathrm{Ca}^{+2}$ & $\mathrm{Mg}^{2+}$ \\
\hline $\begin{array}{l}\text { Enerji } \\
\text { Sarfiyat1 } \\
\mathrm{kWsa} / \mathrm{m}^{3}\end{array}$ & 0,164 & 0,114 & 0,120 & 0,107 & 0,215 \\
\hline $\begin{array}{l}\text { Maliyet } \\
\$ / \mathrm{m}^{3}\end{array}$ & 0,015 & 0,010 & 0,010 & 0,009 & 0,019 \\
\hline & \multicolumn{5}{|c|}{ İçe Suyu Eldesi } \\
\hline $\begin{array}{l}\text { Enerji } \\
\text { Sarfiyat1 } \\
\mathrm{kWsa} / \mathrm{m}^{3}\end{array}$ & 0,113 & 0,092 & 0,152 & 0,072 & 0,187 \\
\hline $\begin{array}{l}\text { Maliyet } \\
\$ / \mathrm{m}^{3}\end{array}$ & 0,01 & 0,008 & 0,014 & 0,007 & 0,016 \\
\hline
\end{tabular}

Tablo'7den görüleceği gibi MCDI prosesi kullanılarak aynı özellikteki suyun farklı amaçlarla arıtılması ile farklı enerji maliyetleri ortaya çıkmakta, ihtiyaca göre düşük maliyetler elde edilebilmektedir.

\section{DEĞERLENDİRME VE SONUÇ}

Sert sular içeriğinde bulunan +2 değerlikli metaller dolayısı ile temas ettikleri yüzeylerde tahribata yol açmakla birlikte suyun tadından ciddi bozulmalara da sebep olmaktadır. Bu olumsuzluklar sebebiyle sert suların yumuşatılması gerekmektedir. Geleneksel yöntemler ekonomik olmamaları, ilave kimyasal gerektirmeleri gibi dezavantajlara sahiptir. Kapasitif deiyonizasyon prosesinin iyon seçici membranlarla donatılmış bir modifikasyonu olan membran kapasitif deiyonizasyon prosesi (MCDI) sertlik gideriminde kullanılabilen, ekonomik, kimyasal gerektirmeyen ekonomik yeni bir teknolojidir.

Sertlik giderimi yapılırken, arıtılacak suyun ne amaçla kullanılacağı, arıtım teknolojisi ve maliyet açısından önemlidir. $\mathrm{Bu}$ çalışmada endüstriyel amaçla kullanılabilecek proses suyu üretimi için farklı $\mathrm{Ca}^{2+}$ ve $\mathrm{Mg}^{2+}$ sertliğine sahip yaklaşık $300 \mathrm{mg} \mathrm{CaCO3/L}$ sertlik içeren numuneler MCDI ile \%90 - \%97 aralığında arıtılma yapılarak proses suyu elde edilmiştir. İçme suyu eldesine yönelik çalışmalarda ise aynı özellikteki numuneler \%71 $\% 82$ oranlarından arıtılarak başarı ile yumuşatılmıştır. Yapılan maliyet analizine göre proses suyu için $0,01-0,02$ \$/m3 enerji maliyet oluşurken içme suyu eldesi için bu değer $0,009-0,016 \$ / \mathrm{m}^{3}$ aralığında değişmektedir.

Sonuç olarak MCDI prosesinin istenen kalitede çıkış suyu elde etmek için esnek olarak kullanılabildiği ve böylece daha düşük maliyetlere sebep olduğu ortaya konmuştur.

\section{KAYNAKÇA}

[1].J. M. Symons, L. C. Bradley, T. C. Cleveland, "The drinking water dictionary", American Water Works Association. Mc Graw Hill, 2000.

[2].Ö. F. Tekbaş, G. Mahir, "Suların Sertlik Dereceleri ve Sağlık Etkileri," TSK Koruyucu Hekim. Bülteni, vol. 3.7, pp. 156-161, 2004.

[3].C. Gabrielli, G. Maurin, H. Francy-Chausson, P. Thery, T. T. M. Tran, and M. Tlili, "Electrochemical water softening: principle and application," Desalination, 2006.

[4].J. S. Park, J. H. Song, K. H. Yeon, and S. H. Moon, "Removal of hardness ions from tap water using electromembrane processes," Desalination, 2007.

[5].B. Boysal, F, Şengörür, "Su Sertliğinin İnsan Sağlığ1 İçin Önemi," SAÜ Fen Bilim. Derg., vol. 13:1, pp. 7-10, 2009.

[6].J. G. Dean, F. L. Bosqui, and K. H. Lanouette, "Removing heavy metals from waste water," Environ. Sci. Technol., 1972.

[7]. A. R. Hauck, S. Sourirajan, "Performance of porous cellulose acetate membranes for the reverse osmosis treatment of hard and waste waters," Environ. Sci. Technol., vol. 3.12, pp. 1269-1275, 1969.

[8].M. K. Nagarajan and H. L. Paine, "Water hardness control by detergent builders," J. Am. Oil Chem. Soc., 1984. [9].B. H. Wiers, R. J. Grosse, and W. a Cilley, "Divalent and trivalent ion exchange with zeolite A.," Environ. Sci. Technol., 1982.

[10].S. Ghizellaoui, A. Chibani, and S. Ghizellaoui, "Use of nanofiltration for partial softening of very hard water," Desalination, 2005. 
[11].K. H. Yeon, J. H. Song, and S. H. Moon, "A study on stack configuration of continuous electrodeionization for removal of heavy metal ions from the primary coolant of a nuclear power plant," Water Res., 2004.

[12].J. H. Song, K. H. Yeon, J. Cho, and S. H. Moon, "Effects of the operating parameters on the reverse osmosis- electrodeionization performance in the production of high purity water," Korean J. Chem. Eng., 2005.

[13].P. Čuda, P. Pospíšil, and J. Tenglerová, "Reverse osmosis in water treatment for boilers," Desalination, 2006. [14].Y. Oren, "Capacitive deionization (CDI) for desalination and water treatment - past, present and future (a review)," Desalination, vol. 228, no. 1-3, pp. 10-29, 2008.

[15].S. Porada, R. Zhao, A. Van Der Wal, V. Presser, and P. M. Biesheuvel, "Review on the science and technology of water desalination by capacitive deionization," Progress in Materials Science. 2013.

[16].M. E. Suss, S. Porada, X. Sun, P. M. Biesheuvel, J. Yoon, and V. Presser, "Water desalination via capacitive deionization: What is it and what can we expect from it?," Energy and Environmental Science. 2015.

[17].H. J. Ahn, J. H. Lee, Y. Jeong, J. H. Lee, C. S. Chi, and H. J. Oh, "Nanostructured carbon cloth electrode for desalination from aqueous solutions," Mater. Sci. Eng. A, 2007.

[18].J. F. Farmer, J. C., Fix, D. V., Mack, G. V., Pekala, R. W., \& Poco, "Capacitive deionization of $\mathrm{NaCl}$ and $\mathrm{NaNO} 3$ solutions with carbon aerogel electrodes," J. Electrochem. Soc., vol. 143(1), p. 159-169., 1996.

[19].P. M. Biesheuvel and A. van der Wal, "Membrane capacitive deionization," J. Memb. Sci., vol. 346, no. 2, pp. 256-262, 2010.

[20].J. B. Lee, K. K. Park, H. M. Eum, and C. W. Lee, "Desalination of a thermal power plant wastewater by membrane capacitive deionization," Desalination, vol. 196, no. 1-3, pp. 125-134, 2006.

[21].T. J. Welgemoed and C. F. Schutte, "Capacitive Deionization Technology ${ }^{\mathrm{TM}}$ : An alternative desalination solution," Desalination, vol. 183, no. 1-3, pp. 327-340, 2005.

[22].H. I. Uzun and E. Debik, "Economical approach to nitrate removal via membrane capacitive deionization," Sep. Purif. Technol., vol. 209, 2019.

[23].P. Długołecki and A. Van Der Wal, "Energy recovery in membrane capacitive deionization," Environ. Sci. Technol., 2013.

[24].E. Debik, H. İ., Uzun, F. İlhan, Y. Avşar, "Yeni Bir Deiyonizasyon Prosesi: Kapasitif Deiyonizasyon," Uluslararası Katılımlı Çevre Sempozyumu, vol. 1, pp. 172177, 2014.

[25].S. J. Seo, H. Jeon, J. K. Lee, G. Y. Kim, D. Park, H. Nojima, J. Lee, and S. H. Moon, "Investigation on removal of hardness ions by capacitive deionization (CDI) for water softening applications," Water Res., vol. 44, no. 7, pp. 2267-2275, 2010. 